\title{
ERRATA
}

Takehiro Ohki • Seiji Uematsu • Yasuhiro Nakamura

Dietrich-Eckhardt Lesemann • Yohachiro Honda

Shinya Tsuda $\cdot$ Ichiro Fujisawa

\section{Characterization of Grapevine Algerian latent virus isolated from nipplefruit (Solanum mammosum) in Japan}

\section{J Gen Plant Pathol (2006) 72: 119-122}

Errors appeared in the article cited above.

The correct name of the third author should be given as Yasuhiro Nakamura, not Yasuhiro Nakayama.

The Acknowledgment should read as follows:

We thank Dr. Masaaki Nakano for providing vine seeds.

T. Ohki $(\bowtie) \cdot$ Y. Honda ${ }^{1} \cdot$ S. Tsuda

National Agricultural Research Center, 3-1-1 Kannondai, Tsukuba

305-8666, Japan

Tel./Fax +81-29-838-8099

e-mail: take2001@affcc.go.jp

S. Uematsu · Y. Nakamura

Chiba Prefectural Agriculture Research Center, Chiba, Japan

D.-E. Lesemann

Federal Biological Research Centre for Agriculture and Forestry,

Braunschweig, Germany

I. Fujisawa

Koibuchi College of Agriculture, Ibaraki, Japan

Present address:

${ }^{1}$ Musashino Seed Co., Ltd., Saitama, Japan 